\title{
A QUALIDADE DE VIDA NO TRABALHO EM UMA PERSPECTIVA CONTRA-
}

\author{
HEGEMÔNICA
}

The quality of life at work in a contra-hegemonic perspective

Mateus de de Freitas Barreiro ${ }^{1}$

Recebido em: 20 ago. 2017

Aceito em: 22 mar. 2018

Resumo: Este artigo tem o objetivo de apresentar como a Qualidade de Vida no Trabalho (QVT) pode ser inserida em mercados competitivos, como o das organizações de Tecnologia da informação (TI) que comumente tem dificuldades para reter talentos. Quando a QVT é trabalhada sob uma óptica preventiva, que se contrapõem as visões assistencialistas e hegemônicas, a QVT poderá ser uma ferramenta que interfere diretamente na motivação dos colaboradores, levando a uma maior eficiência e eficácia organizacional, sendo um dos diferenciais para o êxito nos negócios e no bem-estar dos colaboradores. Esta pesquisa visa focar especificamente a QVT à luz do método de Walton, a partir de um estudo de caso sobre uma microempresa de TI no interior do Estado de São Paulo.

Palavras-Chave: Qualidade de Vida no Trabalho. Método de Walton. Tecnologia da informação.

Abstract: This article aims to present itself as the Quality of Life at Work (QVT) can be inserted in competitive markets, such as the Information Technology (IT) organizations that commonly have difficulty retaining talent. When QVT is crafted under a preventive approach, which counteracts the paternalistic and hegemonic visions, QVT can be a tool that directly affects the motivation of employees, leading to greater organizational efficiency and effectiveness, one of the advantages for success in business and well-being of employees. This research aims to focus specifically QVT the light of Walton method, from a case study of an IT microenterprise in the state of São Paulo.

Keywords: Quality of Life at Work. Walton method. Information Technology.

\section{INTRODUÇÃO}

O mercado de Tecnologia da informação (TI) está em pleno processo de expansão no Brasil, mas não há mão de obra qualificada o suficiente para preencher as vagas e serviços disponíveis no mercado. Além da concorrência entre as organizações de TI para recrutar e reter talentos, os profissionais desta área enfrentam problemas vinculados à Qualidade de Vida no

\footnotetext{
${ }^{1}$ Psicólogo pela PUC-Campinas em 2007, tendo sido bolsista de Iniciação Científica da Fundação de Amparo à Pesquisa do Estado de São Paulo (FAPESP). Mestre em Educação pela UNESP-Marília, com bolsa de pesquisa do CNPq. Está cursando o doutorado em Educação na UNESP-Marília. E-mail: mateusfbb@gmail.com.
} 
Trabalho (QVT), ocasionando alta rotatividade destes profissionais e prejuízos para a organização. Diante desta conjuntura atual, as organizações têm o desafio de subsidiar o bemestar de quem trabalha, conciliando com os pressupostos de eficiência e eficácia nos serviços prestados.

Apesar da crescente produção acadêmica sobre a origem e evolução do conceito de QVT, este artigo visa vincular o conceito de QVT nas organizações que atuam na área de TI. No âmbito das organizações, constata-se que é comum a prática da QVT ser trabalhada de modo assistencialista, na qual não são contempladas as causalidades dos problemas que afetam os colaboradores, tendo em vista que a organização se abdica de uma reestruturação política em gestão de pessoas que possibilite trabalhar QVT de forma consistente (MEDEIROS, 2005).

Primeiramente, o propósito deste artigo, será o de elucidar uma breve discussão teórica acerca do conceito de Qualidade de Vida no Trabalho, enfatizando a importância de se trabalhar a QVT, tendo como pressuposto um paradigma de caráter preventivo, que justifica a escolha pelo método de Walton. Em seguida, será realizada a descrição da metodologia "qualiquantitativa" escolhida para a pesquisa, bem como os instrumentos adotados para proceder ao presente estudo. Por fim, apresenta-se a análise do resultado obtido na pesquisa realizada, visando melhorias consistentes para a QVT, a partir de um planejamento estratégico no setor de $\mathrm{RH}$, de acordo com a realidade de uma microempresa de $\mathrm{TI}$, no interior do Estado de São Paulo.

\section{BREVE HISTÓRICO SOBRE A QUALIDADE DE VIDA NO TRABALHO}

Os estudos sobre a Qualidade de Vida no Trabalho foram iniciados nos anos 50 percorrendo diversas fases. Eric Trist e seus colaboradores do Tavistok Institute de Londres são tidos como os precursores das pesquisas ligadas à Qualidade de Vida no Trabalho. Na década citada, eles começaram uma série de estudos que originou a vertente sócio técnica da organização do trabalho, que visa favorecer a satisfação e o bem-estar do trabalhador. Contudo, somente na década de 60 é que o movimento se impulsionou, tendo como pressuposto básico, a necessidade de se melhorar as formas de organizar o trabalho, e com isso, minimizar os efeitos negativos sobre o trabalhador. Em 1979, ressurgiu a preocupação com a QVT em decorrência da perda de competitividade das indústrias norte-americanas, que levou à investigação dos estilos gerenciais praticados em outros países, que relacionavam os programas de produtividade com a QVT (TOLFO et al, 2001).

O conceito de Qualidade de Vida no Trabalho assume diferentes abordagens ao longo de sua história, trazendo com si características multidisciplinares sobre o trabalho, que se direcionam em diferentes objetivos. Devido à amplitude e variação do conceito de QVT encontrados na literatura, alguns autores sintetizam o conceito QVT em duas abordagens: uma 
clássica, de caráter essencialmente assistencialista, e outra contra-hegemônica (FERREIRA et al., 2006). A definição de QVT sob uma perspectiva assistencialista visa "adaptar o ser humano ao trabalho" por meio de práticas que visam compensar o desgaste provocado por um ambiente organizacional desfavorável (MEDEIROS et al, 2011). Não obstante, estas práticas apenas retiram temporariamente o estímulo adverso, e mantém os mesmos problemas que afetam a QVT dos colaboradores, o que resulta em dificuldades para adesão dos trabalhadores na cultura organizacional.

Em contraposição, ao viés assistencialista, nos últimos anos emanou uma perspectiva de QVT com uma perspectiva contra-hegemônica e preventiva. Uma abordagem preventiva deve considerar aspectos fundamentais como: cultura organizacional, em que se enquadra o Contexto de Produção de Bens e Serviços- CPBS (FERREIRA et al, 2009). Neste sentido o programa de QVT, deve ser relacionado diretamente com a estrutura organizacional para que seja possível ocorrer mudanças consistentes no clima organizacional. Portanto, o presente estudo tem como orientação a vertente de QVT em que o caráter preventivo é preconizado.

Ao analisar, a tendência mundial da livre-concorrência, as organizações no Brasil, começam a se preocupar cada vez mais com as questões envolvam a QVT. Entretanto, até os dias de hoje, o que se observa é a preponderância de programas que não alteram a estrutura organizacional, mas visam compensar ou afastar temporariamente os fatores que afetem a QVT negativamente (MEDEIROS, 2005).

\section{A INSERÇÃO DA QVT NO ÂMBITO DA TECNOLOGIA DA INFORMAÇÃO}

A Tecnologia da informação envolve diversos campos, como o desenvolvimento de sistemas, incluindo a análise, projeto e programação, gerenciamento de bancos de dados, segurança da informação e múltiplas formas de prestação de serviços. Há que se destacar, que a competividade entre as organizações de Tecnologia da informação, a dificuldade para recrutar e manter esses profissionais na organização tem exigido que a gestão, desenvolva políticas voltadas à retenção de talentos, como a Qualidade de Vida no Trabalho (QVT) (MORENO, et al., 2009).

Em empresas de TI, o setor de recursos humanos tem um papel estratégico em relação aos concorrentes, pois através de um estudo da QVT, pode-se elaborar um plano de cargos e salários, voltado para retenção de talentos e redução das altas rotatividades nas organizações (CARMO, 2007).

A revisão da literatura realizada para o presente trabalho mostrou que 0 relacionamento entre empresa e profissionais de TI ainda carece de maiores cuidados. Ao entender como o profissional de TI está reagindo às mudanças gerais que o mercado lhes está apresentando, as empresas poderão modificar suas políticas de atração, desenvolvimento e 
retenção para a área de TI. Nesse sentido, o alinhamento entre as necessidades organizacionais e as necessidades individuais dos profissionais de TI, são fatores cruciais para motivar esses indivíduos (MORENO, et al., 2009).

Os principais motivos que levam os profissionais da área de Tl a trocar de emprego foram: a busca de uma melhor remuneração, problemas de relacionamento com superiores, busca de desafios e oportunidades de carreira. (ROMÃO; ARAÚJO, 2012). Devido aos vários fatores que interferem na qualidade do ambiente de trabalho, é fundamental que o gestor se comunique com os colaboradores, pois assim é possível perceber as causas da insatisfação para dar consistência aos fundamentos que nortearam as mudanças nas práticas de recrutamento e retenção de talentos na área de TI.

Lima e Teixeira (2009) então enaltecem o valor do feedback para avaliação e satisfação do trabalhador. A importância do feedback, diz respeito aos ajustes na organização em caso de dificuldades e de valorização do profissional com desempenho satisfatório. (LIMA; TEIXEIRA, 2009). Neste sentido, o paradigma da QVT adotado pelas organizações de Tecnologia da informação, poderá adotar uma visão que privilegie os aspectos profissionais que incluam a coleta de informação dos colaboradores e o feedback.

\section{CARACTERIZAÇÃO DO OBJETO DE ESTUDO}

Realizou-se um estudo de caso na microempresa com o codinome "SK", que atua no desenvolvimento de software desde 2003 no segmento de Tecnologia da informação. Fundada no interior do estado de São Paulo, a empresa começou desenvolvendo projetos personalizados para diversos segmentos da Indústria, Comércio e Prestação de Serviços. Atualmente possui produtos altamente especializados para vários segmentos, visando atender de forma clara e objetiva as necessidades dos clientes. Conta com uma equipe altamente qualificada que trabalha com as mais modernas tecnologias do mercado, sendo que a empresa SK atua hoje em mais de cinco estados brasileiros, cobrindo desde empresas do varejo até aquelas de segmentos corporativos.

\section{METODOLOGIA}

Dentre as múltiplas perspectivas de QVT encontradas na literatura, optou-se pela utilização do modelo de Walton, que é o mais adequado para atender aos aspectos regionais em se tratando de pesquisa de QVT sugerida por outros estudiosos (MEDEIROS, 2005). Este modelo utilizado na coleta de dados foi elaborado levando em consideração o contexto em que o objeto de pesquisa está inserido, aumentando as propriedades psicométricas (validade e confiabilidade) dos instrumentos para trabalhar com um paradigma de QVT de viés preventivo. 
Walton dividiu os critérios de QVT em oito categorias conceituais, assim descritas:

Tabela1: Modelo de Walton para aferição da QVT

\begin{tabular}{|c|c|}
\hline CRITÉRIOS & INDICADORES QVT \\
\hline 1. COMPENSAÇÃO JUSTA E ADEQUADA & $\begin{array}{l}\text { Equidade interna e externa } \\
\text { Justiça na compensação } \\
\text { Partilha de ganhos de produtividade }\end{array}$ \\
\hline 2. CONDIÇÕES DE TRABALHO & $\begin{array}{l}\text { Jornada de trabalho razoável } \\
\text { Ambiente físico seguro e saudável } \\
\text { Ausência de insalubridade }\end{array}$ \\
\hline 3. USO E DESENVOLVIMENTO DE CAPACIDADES & $\begin{array}{l}\text { Autonomia } \\
\text { Autocontrole relativo } \\
\text { Qualidades múltiplas } \\
\text { Informações sobre o processo total do trabalho }\end{array}$ \\
\hline 4. OPORTUNIDADE DE CRESCIMENTO E SEGURANÇA & $\begin{array}{l}\text { Possibilidade de carreira } \\
\text { Crescimento pessoal } \\
\text { Perspectiva de avanço salarial } \\
\text { Segurança de emprego }\end{array}$ \\
\hline 5. INTEGRAÇÃO SOCIAL NA ORGANIZAÇÃO & $\begin{array}{l}\text { Ausência de preconceitos } \\
\text { Igualdade } \\
\text { Mobilidade } \\
\text { Relacionamento } \\
\text { Senso comunitário }\end{array}$ \\
\hline 6. CONSTITUCIONALISMO & $\begin{array}{l}\text { Direitos de proteção ao trabalhador } \\
\text { Privacidade pessoal } \\
\text { Liberdade de expressão } \\
\text { Tratamento imparcial } \\
\text { Direito trabalhistas }\end{array}$ \\
\hline 7. O TRABALHO E O ESPAÇO TOTAL DE VIDA & $\begin{array}{l}\text { Papel balanceado no trabalho } \\
\text { Estabilidade nos horários } \\
\text { Poucas mudanças geográficas } \\
\text { Tempo para lazer da família }\end{array}$ \\
\hline 8. REVELÂNCIA SOCIAL DO TRABALHO NA VIDA & $\begin{array}{l}\text { Imagem da empresa } \\
\text { Responsabilidade social da empresa } \\
\text { Responsabilidade social pelos produtos } \\
\text { Práticas de emprego }\end{array}$ \\
\hline
\end{tabular}

Fonte: Walton apud FERNANDES (1996).

O procedimento metodológico deste estudo, utilizou dados quantitativos, com base nos indicadores de natureza mensurável que são obtidos através do método de Walton. É também de natureza qualitativa, a partir de entrevistas individuais abertas, análise de discurso, observação direta e leitura de documentos para cruzamento destes dados, possibilitando assim, maior flexibilidade para pesquisar a QVT no contexto de uma microempresa no interior 
do Estado de São Paulo que apresenta menor amostragem de participantes.

A respeito do hibridismo entre o método quantitativo e qualitativo, principalmente na área de administração, esta necessidade surge de uma nova tendência de paradigma metodológico para atender plenamente as necessidades dos pesquisadores e das organizações. Essa dicotomia positivista $\mathrm{x}$ interpretativa, quantitativo $\mathrm{x}$ qualitativo, está cedendo lugar a um modelo alternativo de pesquisa, o chamado quanti-qualitativo, ou o inverso, quali-quantitativo, dependendo do enfoque do trabalho (GOMES; ARAÚJO, 2005).

\section{ANÁLISE DOS RESULTADOS}

A coleta de dados para a viabilização do presente estudo de caso, foi realizado por meio de múltiplas formas de coleta. As visitas à microempresa SK foram realizadas na forma de encontros mensais com duração aproximada de duas horas por visita, entre os meses de Julho e Novembro do ano de 2015.

Em relação à amostra selecionada para aplicação dos questionários, foram abarcados todos colaboradores que atuam na microempresa SK, exceto o Gestor. Quanto ao perfil dos funcionários, 66,66\% são de sexo masculino, sendo um estagiário de TI programador e outro estagiário de TI Help Desk; e 33,34\% do sexo feminino, sendo uma Auxiliar Administrativa, que está no último ano do bacharelado em Administração.

O questionário avaliou cada dimensão dos oito critérios utilizados, a partir de uma escala do tipo Likert, que pode variar de 0 (Muito Insatisfeito) a 5 (Muito Satisfeito) e 2,5 referese à posição de neutralidade, conforme demonstrado abaixo:

Tabela 2: Média geral das respostas afirmativas

\begin{tabular}{l|l|l}
\hline AFIRMATIVAS & MÉDIA & DESVIO PADRÃO \\
\hline $\begin{array}{l}\text { 1-Estou satisfeito em relação ao salário recebido, tendo em vista as minhas } \\
\text { necessidades pessoais e socioeconômicas. }\end{array}$ & 2,83 & 1,26 \\
\hline $\begin{array}{l}\text { 2-A minha remuneração é compatível em relação aos profissionais de } \\
\text { outras empresas que desenvolvem o mesmo trabalho do que eu. }\end{array}$ & 3,00 & 1,09 \\
\hline $\begin{array}{l}\text { 3-Estou satisfeito em relação à remuneração recebida pelas atribuições e } \\
\text { responsabilidades a mim conferidas. }\end{array}$ & 3,50 & 0,59 \\
\hline $\begin{array}{l}\text { 4-Sinto-me a vontade em relação à disposição das minhas ferramentas de } \\
\text { trabalho no local de meu trabalho. }\end{array}$ & 4,66 & 0,57 \\
\hline $\begin{array}{l}\text { 5-A carga horária que cumpro na empresa é satisfatória. } \\
\text { 6-A carga horária de trabalho que cumpro na empresa é suficiente para } \\
\text { desempenhar as minhas tarefas. }\end{array}$ & 4,33 & 0,24 \\
\hline $\begin{array}{l}\text { 7-A empresa me auxilia em minha aprendizagem e aquisição de novos } \\
\text { conhecimentos. }\end{array}$ & 4,16 & 0,07 \\
\hline $\begin{array}{l}\text { 8-A empresa estimula o desenvolvimento de minha iniciativa e a utilização } \\
\text { de habilidades variadas para solucionar problemas. }\end{array}$ & 4,00 & 0,09 \\
\hline \begin{tabular}{l} 
9-A empresa reconhece quando o meu trabalho é realizado com qualidade. \\
\hline
\end{tabular} & 4,16 & 0,07 \\
\hline
\end{tabular}




\begin{tabular}{|c|c|c|}
\hline 10-Sinto que tenho estabilidade no emprego. & 4,66 & 0,57 \\
\hline 11-Tenho oportunidade de crescimento na carreira dentro da empresa. & 3,33 & 0,76 \\
\hline $\begin{array}{l}\text { 12-A empresa me oferece treinamentos necessários para realização do } \\
\text { trabalho. }\end{array}$ & 4,66 & 0,57 \\
\hline $\begin{array}{l}\text { 13-Estou satisfeito com o relacionamento estabelecido com meus colegas } \\
\text { de trabalho. }\end{array}$ & 5,00 & 0,91 \\
\hline 14-Estou satisfeito com o relacionamento estabelecido com meu superior. & 4,66 & 0,57 \\
\hline 15-Estou satisfeito com o relacionamento estabelecido com meus clientes. & 4,66 & 0,57 \\
\hline 16-A empresa reconhece e cumpre os meus direitos trabalhistas & 4,66 & 0,57 \\
\hline $\begin{array}{l}\text { 17-A empresa me permite expressar livremente os meus pensamentos } \\
\text { sobre o trabalho. }\end{array}$ & 4,16 & 0,07 \\
\hline $\begin{array}{l}\text { 18-Percebo que a empresa trata de forma imparcial as decisões referentes } \\
\text { aos funcionários, sem favoritismo. }\end{array}$ & 5,00 & 0,91 \\
\hline $\begin{array}{l}\text { 19-A empresa visa preservar a minha vida pessoal, tempo de descanso sem } \\
\text { a interferência. }\end{array}$ & 4,00 & 0,09 \\
\hline $\begin{array}{l}\text { 20-Procuro equilibrar o tempo dedicado ao trabalho com a minha vida } \\
\text { pessoal. }\end{array}$ & 4,33 & 0,24 \\
\hline $\begin{array}{l}\text { 21-A empresa preza pela estabilidade e previsibilidade de meus horários no } \\
\text { trabalho. }\end{array}$ & 5,00 & 0,91 \\
\hline 22-Percebo que a empresa tem credibilidade perante aos clientes. & 5,00 & 0,91 \\
\hline 23-O meu trabalho é valorizado pela empresa e sociedade. & 3,83 & 0,26 \\
\hline $\begin{array}{l}\text { 24-Percebo que a empresa investe em responsabilidade social apoiando } \\
\text { iniciativas de projetos comunitários. }\end{array}$ & 4,33 & 0,67 \\
\hline MÉDIA DAS MÉDIAS & 4,09 & \\
\hline
\end{tabular}

Fonte: Elabora pelo autor

TABELA 3: Média sobre cada critério da QVT

\begin{tabular}{l|l}
\hline Critérios da QVT & MÉDIA \\
\hline 1.COMPENSAÇÃO JUSTA E ADEQUADA & 3,11 \\
\hline 2.CONDIÇÕES DE TRABALHO & 4,55 \\
\hline $\begin{array}{l}\text { 3.USO E DESENVOLVIMENTO DE } \\
\text { CAPACIDADES }\end{array}$ & 4,05 \\
\hline 4.OPORTUNIDADE DE CRESCIMENTO E SEGURANÇA & 4,21 \\
\hline 5.INTEGRAÇÃO SOCIAL NO TRABALHO & 4,77 \\
\hline 6.CONSTITUCIONALISMO & 4,60 \\
\hline 7.TRABALHO E ESPAÇO TOTAL DA VIDA & 4,44 \\
\hline 8.RELEVÂNCIA SOCIAL DO TRABALHO NA VIDA & 4,38 \\
\hline
\end{tabular}

A análise dos resultados foi elaborada à luz do método de Walton, com um enfoque quali-quantitativo, que possibilitou realizar uma análise que preconizou o caráter preventivo da QVT na organização. Verifica-se que a menor pontuação obtida é proveniente do item referente à compensação justa e adequada (média 3,11). No entanto, em entrevista aberta com os estagiários da área de $\mathrm{TI}$, foi relatado que "o salário de estágio sempre será bem menor 
do que o do profissional de TI contratado, mas que está aprendendo muito no trabalho, bem mais do poderia aprender em outras empresas de maior porte da região". Ainda, em uma análise interna e externa foi constatado que a empresa remunera seus colaboradores de acordo com o mercado da região. Os estagiários de TI também recebem comissões por vendas e treinamentos.

Ao verificar o item sobre a relevância social do trabalho na vida $(4,38)$, foi constatado, que o trabalho exercido pela auxiliar administrativa na empresa, poderia ter suas competências mais aproveitadas, como por exemplo, em relação ao uso de estratégias para resolver impasses com os clientes inadimplentes, e com isso receber uma comissão como os demais colaboradores da empresa. É fundamental que os funcionários entendam a importância de seu trabalho, e participe de outros processos da empresa, que contribuam para maior significação de seu trabalho.

Além do uso e desenvolvimento das capacidades (média 4,05), os estagiários de TI relataram na entrevista o interesse em ser contratado futuramente pela empresa SK, item que se refere à oportunidade de crescimento e segurança (média 4,21). Avaliar este item foi importante, pois a empresa SK está se preparando para expandir seus negócios, devendo estar atenta com a contratação e a retenção de talentos no segmento de TI, que é uma área onde há alta rotatividade dos profissionais.

Há que se destacar a importância para a empresa SK, em relação à questão número 11, que trata sobre o crescimento da carreira dentro da empresa (média 3,33), pois a expansão dos negócios é intrínseca a contratação e retenção de talentos. Portanto, será preciso uma restruturação no setor de recursos humanos, uma vez que a empresa precisará ter mais profissionais de TI. A reestruturação poderá incluir um plano de cargos salários, que terá como objetivo reter e motivar os talentos identificados na organização. Esta reorganização em Gestão em Pessoas vai ao encontro da proposta de caráter preventivo e consistente do paradigma de QVT adotado na presente pesquisa.

Em relação às condições de trabalho $(4,55)$ obteve um escore satisfatório, porém, um dos entrevistados sugeriu a possibilidade da empresa SK "investir em itens, como por exemplo, cadeiras de qualidade para proporcionar maior conforto aos funcionários". A partir da observação direta, verificou-se que a empresa SK optou por não investir significativamente em Layout na parte interna e externa da estrutura física. Este quesito de comunicação visual é importante, pois além de tornar o ambiente de trabalho mais atrativo para a QVT no trabalho, faz com que o colaborador e clientes incorporem uma identificação com a organização.

O quesito que atingiu o escore mais alto foi o de integração social no trabalho $(4,77)$; na observação direta e entrevistas abertas, viu-se que o relacionamento interpessoal entre os colaboradores e o Gerente é satisfatório, tornando o trabalho e espaço total da vida $(4,44)$ muito agradável e participativo. $\mathrm{O}$ estilo de liderança do Gerente permite que os colaboradores 
se interessem pelo trabalho, mantendo assim, os funcionários motivados e satisfeitos com a QVT.

Durante a realização do trabalho foi observado à organização do Gerente em controlar minuciosamente as diversas variáveis quantitativas sobre os processos organizacionais, bem como a preocupação em motivar os funcionários através de treinamentos, reajustes de carga horária e análises contingenciais do ambiente de trabalho que interferem na QVT. Sem dúvidas, a QVT de carácter preventivo depende muito do estilo de liderança na organização.

\section{CONCLUSÃO}

A Tecnologia da informação apresenta desafios específicos para trabalhar a QVT em diferentes organizações, como a questão da retenção de talentos e capital intelectual. Por se tratar de uma microempresa esses desafios apresentam características peculiares que requerem procedimentos metodológicos adequados para conciliar as práticas de pesquisa acadêmicas e atender a realidade organizacional.

O modelo de Walton possibilitou entender cada item da QVT separadamente, porém, em alguns momentos foi necessário recorrer à entrevista aberta para realizar perguntas de maior alcance sobre determinado item, bem como a observação direta do ambiente.

A empresa SK já demonstrava interesse pela QVT antes da realização de iniciar a presente pesquisa, o que facilitou muito a aceitação para trabalhar os aspectos que interferem na motivação dos colabores. Após a análise dos resultados obtidos no presente artigo, futuramente será possível evidenciar ainda mais a relevância do caráter preventivo da QVT nas organizações de Tecnologia da informação.

\section{REFERÊNCIAS}

CARMO, R. M. A importância do talento humano como recurso estratégico: um estudo sobre as políticas para retenção de profissionais em organizações de Tecnologia da Informação. 2007. 104 f. Dissertação (Mestrado em Gestão do Conhecimento e da Tecnologia da Informação) - Universidade Católica de Brasília, Brasília, 2007.

FERNANDES, E. Qualidade de vida no trabalho: como medir para melhorar. Casa da Qualidade Editora Lida, Salvador, 1996.

FERREIRA, M. C.; ALVES, L; TOSTES, N. Gestão de qualidade de vida no trabalho (QVT) no serviço público federal: o descompasso entre problemas e práticas gerenciais. Psicologia: teoria e pesquisa, v. 25, n. 3, p. 319-327, 2006.

FERREIRA, R. et al. Concepção e implantação de um programa de qualidade de vida no trabalho no setor público: o papel dos gestores. Revista de Administração da Universidade de 
São Paulo, v. 44, n. 2, p. 147-157, 2009.

GOMES, F.; ARAÚJO, R. Pesquisa Quanti-Qualitativa em Administração: uma visão holística do objeto em estudo. In: SEMINÁRIOS EM ADMINISTRAÇÃO, 8, 2005, São Paulo. Anais...São Paulo: FEA/USP, 2005.

LIMA, O; TEIXEIRA, P.C. Direcionamento estratégico e gestão de pessoas nas organizações. São Paulo: Atlas, 2009.

MEDEIROS, L. F. Avaliação da Satisfação no Trabalho com o uso de Indicadores de Qualidade de Vida no Trabalho. In: XXV ENCONTRO NACIONAL DE ENGENHARIA DE PRODUÇÃO, Porto Alegre, Porto Alegre, RS, 2005.

MEDEIROS, L. F.; FERREIRA, M. C. Qualidade de Vida no Trabalho: uma revisão da produção científica de 1995-2009. Gestão Contemporânea, n. 9, 2011.

MORENO A. et al. Carreira e relações de trabalho na prestação de serviços de tecnologia da informação: a visão dos profissionais de TI e seus gerentes. Journal of Information Systems and Technology Management: JISTEM, v. 6, n. 3, p. 437, 2009.

ROMÃO, Maria; ARAÚJO, Tatiane. Retenção de capital intelectuaL no setor de tecnologia da informação de Brasília-DF. Universitas Gestão e TI, v.2, n.2, p.17-28, jul/dez. 2012.

TOLFO, S. R.; PICCININI C. As melhores empresas para trabalhar no Brasil e a qualidade de vida no trabalho: disjunções entre a teoria e a prática. Revista de administração contemporânea, $v$. 5, n. 1, p. 165-193, 2001. 